\title{
SOBRE EL EXCESO DE OBEDIENCIA Y OTROS EXCESOS (UN ANTICIPO) *
}

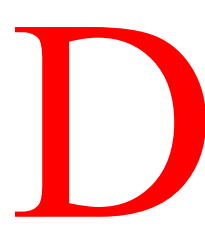

esde que tuve la osadía de intervenir o entrometerme en el debate sobre la «obediencia (o desobediencia) al Derecho» provocado entre nuestros iusfilósofos por un ya célebre -merecidamente célebre- trabajo del profesor González Vicén, me he ganado -supongo que también merecidamente- algún que otro varapalo, varapalo que soporto muy a gusto si la razón para merecerlo es mi acuerdo con don Felipe o, en cualquier caso, mi desacuerdo con sus críticos.

Pero como tampoco es cosa de escudarse en aquél y traspasarle los varapalos dirigidos a mí, creo que va siendo hora de responder a algunos de ellos por mi cuenta y razón. Eso es lo que hace ya algún tiempo prometí a un par de amigos y compañeros, presentes hoy aquí, como lo son Adela Cortina y Eusebio Fernández: a saber, les tengo prometida una respuesta que probablemente titularé «Sobre el exceso de obediencia y otros excesos». Mas, dado que el tiempo de que dispongo hoy no alcanza para eso, me limitaré a esbozar un breve anticipo de lo que podría ser dicha respuesta, sobre la que sigo prometiendo volver en mejor ocasión.

Para recordar en dos palabras los términos de la discusión, permítanme una somera referencia a su literatura. Concebido como un amistoso intento de «terciar» en el debate sobre la obediencia al Derecho que enfrentaba a los profesores Felipe González Vicén y Elías Díaz -con quien vendría a alinearse, entre otros, el profesor Manuel Atienza-, publiqué en su día un artículo bajo el título de «La obediencia al Derecho y el imperativo de la disidencia (Una intrusión en un debate» (Sistema, 70, 1986), artículo recientemente comentado por Adela Cortina en su ensayo «La calidad moral del principio ético de universalización» (Sistema, 77, 1987) y por Eusebio Fernández en un capítulo de su libro, del mismo año, precisamente titulado La obediencia al Derecho. El planteamiento de mi artículo, por lo demás, daba por presupuesto que no hacía enteramente mías en él las tesis de ninguno de los contendientes originarios, aun cuando no negara allí, como tampoco niego hoy, que mis simpatías se inclinaban bastante más del lado de la juventud que del de la respetabilidad, esto es, del lado de don Felipe y no del de Elías.

Frente a Elías Díaz, yo discrepaba de su idea de que «si la conciencia individual puede fundamentar la desobediencia ética al Derecho, la

\footnotetext{
* Palabras pronunciadas por el autor en la mesa redonda sobre «Filosofía y Derecho en la obra de Felipe González Vicén», X Jornadas de Filosofía Jurídica y Social, Universidad de Alicante, 18 de diciembre de 1987.
} 
misma razón hay para que fundamente éticamente su obediencia». En mi opinión, tal tesis descansaba en la postulación de una falsa simetría, en especial si se sostiene -como Elías Díaz lo ha hecho- que «el Derecho... es... un intento de aunar criterios éticos individuales expresados socialmente como soberanía popular y regla de las mayorías». Pues me parecía, y me parece, que -mientras la obediencia al Derecho entraña la vinculación de la conciencia individual a otras conciencias individuales (manifestada, por lo menos, en el voto conjunto a la hora de elegir a los representantes del electorado que integran el poder legislativo)- la desobediencia al Derecho entrañaría más bien la desvinculación de la voluntad del individuo respecto de la voluntad colectiva, presumiblemente mayoritaria, plasmada en el Derecho. Pero, esto sentado, yo no iba tan lejos como González Vicén ni llegaba a decir con él que, siendo la «obligación jurídica» -como lo es- «de naturaleza heterónoma y coactiva», ni tan siquiera pueda hablarse de «un fundamento ético de la obediencia al Derecho». Por el contrario, creo que ese fundamento es de índole contractual y yo mismo citaba a este respecto la sofisticada versión habermasiana del neocontractualismo como un buen ejemplo, y un ejemplo contemporáneo, de teoría al servicio de semejante fundamentación, pues para mí estaba claro que la idea de «que no exista ningún campo de coincidencia entre el Derecho y la Ética es, en verdad, inaceptable para quien no sea un positivista», si bien me veía en la necesidad de añadir a continuación que no menos vitando es el peligro opuesto, el peligro, a saber, «de que la Ética y el Derecho se confundan más de lo que sería de desear y no menos inaceptablemente».

Precisando un poco más, lo que añadía a continuación es que tan importante o más que aquel problema de la fundamentación ética de la obligación de obedecer al Derecho -o, generalizando, de la obligación de respetar la Democracia, que tiene el mismo fundamento contractual- era el problema de los límites de dicha obligación. Pues la obediencia al Derecho o el respeto a la Democracia no garantizan por sí solos que el Derecho que obedecemos o la Democracia que respetamos sean justos. Y aquí es precisamente donde la Ética entra en acción. Pues la cuestión de la justicia es una de esas que la Ética nunca podrá pasar por alto ni dejar en otras manos. No lo podrá hacer, pongamos por caso, a la hora de preguntarnos si hay ocasiones -como cuando un gobierno democrático actúa injustamente aunque no deje de actuar dentro de la legalidad vigente, lo que quiere decir que la legalidad vigente podría ver cuestionada su legitimidad- en las que estamos éticamente obligados a desobedecer, aun si jurídicamente no lo estamos o incluso estamos obligados a prestar a la ley nuestra obediencia.

Desde el punto de vista de la argumentación llevada a cabo en mi artículo, yo creía ver el fundamento de la obediencia ética al Derecho en la célebre versión del imperativo categórico kantiano que nos dice «Obra sólo según una máxima tal que puedas querer al mismo tiempo que se torne ley universal», imperativo este que Habermas ha reformulado en los siguientes términos de su ética comunicativa: «En lugar de considerar como válida cualquier máxima que quieras ver convertida en ley universal, somete tu máxima a la consideración de todos los demás 
con el fin de hacer valer discursivamente -esto es, democráticamente- su pretensión de universalidad». Ahora bien, al imperativo kantiano de la universalidad se le ha podido reprochar que no hay nada que impida hacerlo suyo a un racista fanático dispuesto a ser gaseado si se descubre en él la menor mancha de impureza racial. Y, de análoga manera, nada tampoco impediría que una habermasiana comunidad de comunicación -y hasta la misma humanidad en su conjunto, en el improbable supuesto de verse convertida en una comunidad de comunicación, habermasiana o no- pudiera legislar injustamente y hasta hacerlo de forma atentatoria para la condición humana. En cuyo caso, claro, estaríamos autorizados a desobedecer esa legislación. Y, si alguien me demandase un fundamento a este respecto, yo no tendría en rigor otro mejor que una nueva versión, distinta de la anterior, del imperativo categórico kantiano, como la que nos dice «Obra de modo tal que tomes a la humanidad, tanto en tu persona como en la de cualquier otro, como un fin al mismo tiempo y nunca meramente como un medio». Y aquí es donde, por fin, entran en liza mis queridos Adela Cortina y Eusebio Fernández.

En la imposibilidad de atender en esta sesión a lo que sus respectivos argumentos tienen de específico, me referiré sólo a lo que tienen de común. Pues bien, lo que en nuestro caso matrimonia a esta philosophical couple es no sólo su común reluctancia hacia mi posición, sino el hecho de argumentar frente a ella amparándose en Kant y acusándome de no haberle interpretado bien. Puesto que se trata, como se trata, de dos filósofos obedientes, nada de extraño tiene que argumenten en mi contra basándose en argumentos de autoridad.

Para Adela Cortina -comenzaré por ella-, no hace al caso contraponer como yo las contraponía las dos versiones anteriormente mencionadas del imperativo categórico, toda vez que el propio Kant las consideraba -las palabras son suyas- «idénticas en el fondo». Eso es muy cierto. Como también lo es que Kant afirmaría que «el imperativo categórico es uno y sólo uno» y, sin embargo, contamos con diversas versiones del mismo: las tres clásicamente reconocidas, que para algunos intérpretes serían cinco y para otros, siete u ocho. En mi opinión, habría en realidad tantos imperativos categóricos cuantos imperativos demos en considerar revestidos de categoricidad, es decir, de la forma «Debo hacer tal y tal cosa» en lugar de «Debo hacer tal y tal cosa si quiero conseguir tal y tal otra». Idénticas en el fondo o no -lo que pensara Kant, después de todo, tampoco importa tanto, pues no estamos haciendo aquí exegética de ese su pensamiento-, yo he distinguido entre dos de aquellas versiones a las que corresponde distinto alcance y peso: el imperativo de obrar de modo que nuestras máximas morales puedan ser tenidas por leyes universales -al que llamé «imperativo de la universalidad»- y el imperativo de obrar de modo que ningún ser humano sea tomado por un medio sin ser tenido al mismo tiempo por un fin en sí, al que llamaremos «imperativo de los fines». La diferencia básica entre ellos -pues alguna «diferencia básica» tendrá que haber para poderles asignar funciones asimismo diferentes- vendría a ser, para nuestros efectos, la siguiente. 
En la reformulación habermasiana del imperativo de la universalidad, éste habría de resolver en la consulta democrática. ¿Cómo, si no, vendría a acordar una comunidad qué máximas morales merecen ser universalizadas? Supongamos que parte de la comunidad esté a favor y parte en contra de la práctica de relaciones sexuales interraciales. En última instancia, se impondría el recuento de votos entre la población. Pero, naturalmente, eso no agota la cuestión. Pues si de aquel recuento sale la prohibición de que dos personas de distinta raza se relacionen sexualmente una con otra, alguien podría alegar que esas personas no están siendo tratadas como fines en sí mismos y que ningún acuerdo democrático, por más que cuente a su favor con la regla de las mayorías, basta a apearles de esa condición. Kant probablemente no hubiera visto con malos ojos la reformulación del imperativo de la universalidad a manos de Habermas. Pero, a no dudarlo, se habría mostrado sorprendido de oír decir que la dignidad humana, que es lo que se halla en juego en el imperativo de los fines, necesita ser sometida a referéndum.

Por escasas que fueran en la comunidad de marras las personas contrarias a la discriminación racial frente a la opinión racista del abrumador resto de sus miembros, aquéllas se hallarían éticamente autorizadas a desobedecer. O así es, por lo menos, como yo tendería a ver las cosas. ¿Pero es también ese el modo como tendía a verlas Kant?

Lo que Eusebio Fernández me reprocha es haberme inspirado en Kant para fundamentar la posibilidad de la desobediencia ética al Derecho, desobediencia ésta que Kant habría expresamente repudiado, como lo muestra sin ambages su desfavorable actitud ante el llamado «derecho de resistencia». Ahora bien, la actitud de Kant ante el (mal) llamado derecho de resistencia constituye -como el propio González Vicén ha recordadouna vexata quaestio de la filosofía jurídica y política de Kant, quien -junto al repudio de aquel supuesto derecho- no vaciló en expresar su entusiasmo por los levantamientos y rebeliones de Irlanda y los Estados Unidos y, por supuesto, la Revolución Francesa. De acuerdo con González Vicén, la negación kantiana del (mal) llamado derecho de resistencia ha de entenderse como respuesta a un problema de lógica jurídica por parte de un filósofo para el cual el Derecho resultaba ser ya Derecho positivo en cuanto diferente del viejo Derecho natural. Pues, en términos de Derecho positivo, sería en efecto jurídicamente contradictorio admitir un supuesto derecho de resistencia, o un derecho a la rebelión, que viniera a arruinar el propio marco del ordenamiento jurídico dentro del que se inscribe. En su magistral La Filosofía del Estado en Kant (reeditada en el volumen De Kant a Marx), González Vicén aduce un texto de un kantiano de la primera generación, Jakob Fries, que compendia -y compendia bien- cuanto se acaba de exponer: «El pueblo no tiene ningún derecho a la insurrección ni el soberano ningún derecho en contra... En la insurrección no tiene lugar una contienda jurídica, sino una lucha regida por la violencia... En toda insurrección, y en toda represión de ella, se trata sólo de un problema de fuerza».

Por lo que a mí respecta, yo -como buen lector del profesor González Vicén- no hablé jamás de un derecho de resistencia. Lo que decía, y lo decía por cuenta propia -sin necesidad, por lo tanto, de atribuírselo 
tampoco a Kant-, era más bien esto otro. A saber, que nadie tiene derecho a imponer su voluntad a la mayoría cuando no está de acuerdo con la decisión colectiva, pero tampoco tiene obligación moral -aunque la pueda tener jurídica- de obedecer tal decisión cuando ésta sea injusta. Y que cuando dicha injusticia implica el trato de otros seres humanos como medios y no como fines en sí mismos, como objetos y no como sujetos, puede en cambio tener la obligación moral -aunque no la tenga jurídica, e incluso tenga una obligación jurídica de signo opuesto- no sólo ya de resistir pasivamente a la decisión mayoritaria, sino incluso la de oponerse a ella activamente, esto es, la obligación de disentir. De ahí, en fin, que mi artículo no mencionase para nada un supuesto derecho a la resistencia, sino hablase más bien, en su lugar, del imperativo de la disidencia.

Y, por supuesto, la decisión acerca de si hemos de resistir o disentir ha de corresponder en última instancia al tribunal de nuestra conciencia. En opinión de Adela Cortina, «la conciencia de que habla González Vicén es más existencialista que kantiana». Pero no creo que haya incompatibilidad entre una cosa y otra. Después de todo, un existencialista puede hacer suyo el principio kantiano de universalización. Que era, no necesito recordarlo, lo que hacía Sartre al advertirnos que, cuando alguien elige moralmente, elige por toda la humanidad. Y, recíprocamente, el formalismo ético de Kant, tan a menudo mal interpretado, constituye en rigor el polo opuesto de lo que se ha llamado la «moral codicial», es decir, la «moral cerrada» de un determinado código moral, lo que en algún sentido convierte a la filosofía moral kantiana en precursora de aquello que entendemos hoy por «éticas sin código». Entre las que, tampoco necesito recordarlo, se encontraba en su día la moral existencialista de la situación.

Pero, por lo demás, me parece que lo de menos es tratar de catalogar aquí -con la etiqueta de «kantiana» o de «existencialista», o de ambas cosas a la vez- la peculiar aportación de don Felipe González Vicén al «individualismo ético», que es, en definitiva, aquella posición para la cual no hay ni podría haber ninguna instancia ética superior a la conciencia individual, algo que pocos como él han sabido expresar con tanta precisión ni tan hermosamente y por lo que -dejando aparte ahora sus muchos otros méritos- merece este homenaje de sus colegas y, desde luego, la modestísima contribución al mismo de este intruso: «La limitación de la obediencia al Derecho por la decisión ética individual significa el intento de salvar, siquiera negativamente y de modo esporádico, una mínima parcela de sentido humano en un orden social destinado en sí al mantenimiento y aseguración de relaciones específicas de poder... En una sociedad pluralista y en cambio acelerado, que asiste a la desintegración de todas las instancias heredadas, los esquemas de comportamiento no proceden ya de la tradición, sino sólo de la interioridad... Esta interioridad, la conciencia, puede ser desmenuzada hasta sus últimos extremos por el psicoanálisis o la sociología, pero siempre queda en pie, como última verdad, que es la única instancia a la que podemos apelar sin duda para nuestra conducta» (Felipe González Vicén, «La obediencia al Derecho», Estudios de Filosofia del Derecho, La Laguna, 1979).

\section{DOXA 4 (1987)}

